\title{
Biological peculiarities and characteristics of Erodium tataricum WILLD. cenopopulation in Khakasia
}

\author{
Irina Barsukova*, and Tatiana Leonova \\ Khakas State University n.a. N.F. Katanov, 655017, Russia
}

\begin{abstract}
Biological and structural peculiarities of Erodium tataricum Willd. cenopopulations in natural surroundings of Khakasia are examined. It is found out that the species make two vegetal forms under the changing environmental conditions. Ontogeny is complete, regeneration does not take place. Two types of ontogeny are found out: morphological and dynamic (according to the rate of growth). Examined Erodium tataricum Willd. cenopopulations are normal and incomplete. They are characterized by left-sided and bimodal ontogenetic spectra.
\end{abstract}

\section{Introduction}

Erodium tataricum Willd. (family Geraniaceae Juss.) - perennial herbaceous plant has a status of 3(R) in the Red List of Threatened Species of Russian Federation (2008) and in the Red List of Threatened Species of Khakasia (2012). It is paleoendemic, the area of species does not exceed the boarders of Khakasia [2]. Its basic area is between the rivers Belyi Iyus and Son in forest-steppe and steppe zone on stony and rank slopes. In connection with this, the biological and structural examination of the rare species of its cenotic population will allow to predict further development of cenopopulation and to take special activities for its protection. There is very little information about E. tataricum biology. The goal is to examine biological and structural peculiarities of E. tataricum cenopopulations in natural surroundings of Khakasia.

\section{Material and methods}

Cenopopulations (CP) were described in Minusinsk basin on the territory of IyusoShirinskiy steppe in 2016-2018. Geobotanic descriptions were performed according to the established methodology [3]. The concept of its discreet description was taken into account when studying the ontogeny [4-7]. Biometric characteristics of species was made on the basis of the following features: the height of plants, the number of leaves and their length, the number of vegetal and generative shoots, the number of flowers, the length and diameter of caudex. The total number of E. tataricum specimens under study was 89 .

\footnotetext{
*Corresponding author: saphronovairina@mail.ru
} 
Ontogenetic structure of CP was performed with the use of population genetic approach [8-9]. 16-20 fixed areolas $1 \mathrm{~m}^{2}$ in size were put in transects, all species were mapped with marking their ontogenetic condition. A species was taken as a unit of time. Understanding of L.B. Zaugolnova (1994) served as a basis when building the ontogenetic spectra and structure characteristics of CP. Demographic indices were used: age index $(\Delta)$ and efficiency index $(\omega)[10]$. Space structure was examined according to the methodology of Y. Odum (1986).

CP 1 was described in Shirinskiy region 12-15 m. away from the village Black Lake along the right bank of the river Belyi Iyus on the South-West slope of the hill in Karaganovaya motley grass-grasses petrophytic true steppe. The total projective cover (TPC) of herb layer was 40-45\% (Poa stepposa (Krylov) Roshev., P. botryoides (Trin. ex Griseb.) Kom., Festuca valesiaca Schleich. ex Gaudin, Artemisia frigida Willd., Potentilla acaulis L.). Shrubbage accounts for 15-20\%. The dominant position occupied Caragana pygmaea (L.) DC. Dasiphora fruticosa (L.) Rydb. and Cotoneaster melanocarpus Fisch. ex Blytt were growing sporadically in hollows.

CP 2 was examined on the border with the State nature reserve «Khakassky» («The Lake Itkul», Shirinsky region) on the South-East slope of the hill in Karaganovaya forbfecue-feather grass lithophyte true steppe (Caragana pygmaea, Festuca valesiaca, Koeleria cristata (L.) Pers., Orostachys spinosa (L.) C. A. Mey., Potentilla acaulis). The total projective cover (TPC) of herb layer was 50-55\%. Projective cover of species in plant community made up $1 \%$.

\section{Results and discussion}

According to the performed examination, E. tataricum is grown in similar plant communities. The dominant species are Festuca valesiaca, Koeleria cristata, Poa stepposa, P. botryoides, Carex duriuscula C. A. Mey., Carex pediformis C. A. Mey. Orostachys spinosa, Potentilla acaulis, Artemisia frigida, Alyssum lenense Adams, A. obovatum (C.A. Mey.) Turcz., Thymus serpyllum L., Galium verum L., Pulsatilla reverdattoi Polozhij \& Malzeva and others accompany it.

E. tataricum - herbaceous taproot multi-headed polycarpous plant with assimilated rosette-like shoots of non-succulentus type. 3-5 (rarely 6-8) rosette-like shoots are formed on plant of a mature genesic ontogenetic condition. Their maximum height is $10 \mathrm{~cm}$ (more often 4-6 cm). The leaves are macropodous and pinnatifid. Their number on one vegetative shoot is 5-7. 2-4 genesic shoots $9 \mathrm{~cm}$ in height are developed in sinuses, each bearing 2-4 flowers. The plant is wolly, with white long pressed hair with a touch of grandular hair (specifically on flower-bearing stem and a flower cup). The presence of caudex make a species static - monocentric. Caudex multi-headed forms 3-9 branches 4,0-4.8 cm in height. The diameter of caudex in its expanded part varies from 0,9 to $1.7 \mathrm{~cm}$.

E. tataricum ontogeny is complete, it has 10 ontogenetic stages (4 periods). Particulation takes place in old generative, more often in old vegetative ontogenetic stage, as a rule it does not cause regeneration, parts of taproot plant fade the same year. $E$. tataricum reproduction is performed only by seeds.

A stable existence of E. tataricum CP in constantly changing environmental conditions provides biodiversity of its ontogeny.

Morphological biodiversity is observed when there is a controlled burning of steppe vegetation. Rhizomatous taproot system develops. Rhizoma reaches the length no more than 3-4 cm with orthotropic direction of pigeony origin. Besides, unfavorable conditions (a controlled burning of steppe vegetation in spring and in autumn, absence of rain for a long time) cause difference in pace of development. Species does not reach mature generative ontogenetic stage and consequently graduate from young stage into old generative 
ontogenetic stage. Shorter duration of one of the ontogenetic stages and quick transition into the succeeding one record the acceleration of species ontogeny.

All CP under study are characterized as normal. In CP 1 a left-sided ontogenetic spectrum with absolute maximum on young generative species is formed $(36,1 \%)$. In CP 2 there is a maximum on the mature generative species $(35,7 \%)$, besides, there is a high percentage of species in immature $(28,6 \%)$ and young generative $(21,4 \%)$ ontogenetic condition.

Left-sided ontogenetic spectrum is formed due to the concentration of specimens of seed origin. The spectrum is dynamic, the number of young specimens is unstable, and they undergo a process of big elimination. Fire influences them negatively. However, a controlled burning of steppe vegetation reduces projective cover of herb layer which causes the emergence of E. tataricum seedlings on open territories. Germinated seeds and juvenile, immature and virgin plants fade, if there is no rain in summer period. A part of pre-generative specimens fade because of low temperature in winter period.

Bimodal ontogenetic spectrum of CP 2 proves its ability to self-maintenance with the help of seeds. The difference between young and mature generative species is insignificant which allows considering the spectrum as a left-sided variant.

In CP under study shoots and species of senile and sultrily ontogenetic condition are often absent. Absence of shoots is connected with the fact that seeds of E. tataricum are easily washed off by rain and blown by winds. Absence of post-generative stage are caused by quick death of old species and are typical of plants having caudex.

According to the "delta-omega" classification of L.A. Zivotovskiy (2001) both CP grow ripe. Efficiency index does not reach 0,34, age index - 0,73.

Distribution of E. tataricum species is accidental. It is determined by seed reproduction and peculiarities of the micro-relief (as a rule it is represented by slopes and vegetation is blown by winds). Species are distributed in groups when seeds fall from the case near female parent. It is rarely described.

\section{Conclusion}

E. tataricum is characterized by narrow ecological amplitude and grows exclusively in petrophytic true steppe on the territory of Khakasia. Diversity of ontogeny is found out during controlled burning of steppe vegetation and with the absence of rain. As a result of adaptation species develop rhizomatous taproot system, duration of ontogenetic conditions become shorter, possibility of seed sprouting increases because of the reduction of total projective cover of herb layer. Cenopopulation is normal and incomplete with left-sided and bimodal ontogenetic spectra. Distribution of species is accidental, determined by seed reproduction.

A research is done with financial support of the Russian Foundation for Basic Research № 18-44-190007 p_a; № 18-44-190006 p_a.

\section{References}

1. Red List of Threatened Species of Russian Federation. Plants and mushrooms (M., 2008)

2. E.S. Ankipovich, D.N. Shaulo, N.V. Sedelnikova et al., Red List of Threatened Species of Khakasia: rare and endangered species of plants and mushrooms. (Novosibirsk, 2012).

3. A.A. Korchagin, Field geobotany, 3 (M.-L., Nauka, 1964)

4. T. A. Rabotnov, Tr. BIN USSR, 3, 6 (1950) 
5. A.A. Uranov, Biol. sciences, 2 (1975)

6. Plant coenopopulations: general terms and structure (M, Nauka, 1976)

7. Plant coenopopulations: basic concepts and structure (M, Nauka, 1988)

8. L.B. Zaugolnova, Structure population of seed plants and related monitoring problems, Diss. (St. Petersburg, 1994)

9. L.A. Zhukova, Population Life of the Meadow Plants (Yoshkar-Ola, Lanar, 1995)

10. L.A. Zhivotovsky, Rus. J. Ecol., 1 (2001)

11. Yu. Odum, Ecology, 2 (M, Nauka, 1986) 